\title{
Cross-Sectional Associations Between Violent Video and Computer Game Playing and Weapon Carrying in a National Cohort of Children
}

\author{
Michele L. Ybarra $^{1 *}$, L. Rowell Huesmann ${ }^{2}$, Josephine D. Korchmaros ${ }^{1}$, and Sari L. Reisner ${ }^{1,3}$ \\ ${ }^{1}$ Center for Innovative Public Health Research, San Clemente, California \\ ${ }^{2}$ University of Michigan, Ann Arbor, Michigan \\ ${ }^{3}$ Harvard School of Public Health, Boston, Massachusetts
}

: : : : : : : : : : : : : : : : : : : : : : : : : : : : : : : : : : :

Data were collected from 9 to 18 year olds surveyed nationally in a three-wave longitudinal survey. The population-average (generalized estimating equation, GEE) odds of carrying a weapon to school in the last month were estimated as a function of pastyear exposure to violent content in video, computer, and Internet games, as well as peer aggression and biological sex. The sample included youth who were at risk for both the exposure (i.e., game play) and the outcome (i.e., who attended public or private school). 3,397 observations from 1,489 youth were included in analyses. 1.4\% of youth reported carrying a weapon to school in the last month and $69 \%$ reported that at least some of the games they played depicted violence. After adjusting for other potentially influential characteristics (e.g., aggressive behavior), playing at least some violent games in the past year was associated with a fourfold increase in odds of also reporting carrying a weapon to school in the last month. Although youth who reported frequent and intense peer victimization in the past year were more likely to report carrying a weapon to school in the last month, this relation was explained by other influential characteristics. Consistent with the predictions of social-cognitive, observational learning theory, this study supports the hypothesis that carrying weapons to school is associated with violent game play. As one of the first studies of its kind, findings should be interpreted cautiously and need to be replicated. Aggr. Behav. 40:345-358, 2014. (C) 2014 Wiley Periodicals, Inc.

: : : : : : : : : : : : : : : : : : : : : : : : : : : : : : : : : : : :

Keywords: youth violence; weapons; video games; adolescence; schools

\section{INTRODUCTION}

Weapon carrying in school is a significant adolescent health problem (Murnan, Dake, \& Price, 2004). An estimated $7 \%$ of $9-12$ th graders carried a weapon to school in the past 30 days and $8 \%$ of high school students were threatened or injured with a weapon on school property in the past 12 months (Centers for Disease Control and Prevention, 2006). Risk factors for weapon carrying include aggressive and delinquent behaviors, such as involvement in physical fights, substance use, school suspensions, and exhibiting a "temper" (Brener, Lowry, Barrios, Simon, \& Eaton, 2004; Cotten et al., 1994; DuRant, Krowchuk, Kreiter, Sinal, \& Woods, 1999; Nansel, Overpeck, Haynie, Ruan, \& Scheidt, 2003; Webster, Gainer, \& Champion, 1993). Research also suggests that youth who have a history of adverse childhood experiences, such as substance abuse in the family (Duke, Pettingell, McMorris, \& Borowsky, 2010; Leeb, Barker, \& Strine, 2007), are more likely to carry weapons to school. Thus, youth at risk for weapon carrying may have a combination of experiences reflecting victimization and internalizing behaviors, as well as perpetration and externalizing behaviors. Little research has examined both internalizing and externalizing behaviors simultaneously.

Bullying and other types of peer victimization may be related to weapon carrying, although the existing research is scant. Previous research suggests that youth

Contract grant sponsor: Centers for Disease Control and Prevention (CDC); contract grant number: U49/CE000206.

Conflicts of interest: None.

*Correspondence to: Michele L. Ybarra, MPH, PhD, 555 El Camino Real \#A347, San Clemente, CA 92672-6745.

E-mail: Michele@InnovativePublicHealth.org

Received 4 April 2013; Accepted 3 December 2013

DOI: $10.1002 / \mathrm{ab} .21526$

Published online 24 January 2014 in Wiley Online Library

(wileyonlinelibrary.com). 
who are bullied (Nansel et al., 2003) and feel the need for self-protection (Sheley \& Wright, 1993) are more likely to bring weapons to school. Webster et al. (1993) examined, among inner-city middle school youth, the likelihood of weapon carrying given either aggressive delinquency or defensive behavior such as might be seen for youth who are being bullied. The researchers found that aggressive delinquency but not defensive behavior was associated with gun carrying. How these results might extend to a more representative sample of youth is unclear.

Additionally deficient in previous research about weapon carrying is the examination of violent media's potential influence. Research that does exists focuses on school shootings because of their fatal impact, rather than $\mathrm{ib}$ the more general behavior of carrying a weapon to school. Although school shootings are sometimes discussed in association with the problem of video game violence (Anderson, 2004), extrapolating the existing empirical research to definitive statements about the causes of school violence, particularly school shootings, is problematic. Ferguson (2008) conducted a review of the retrospective studies that have been done and concluded that there was insufficient evidence linking violent video games to school shootings. Among the research cited, Ferguson notes a review of school shooters between 1974 and 2000 that concludes that the characteristics of perpetrators is rather diverse and that no particular characteristic, including violent game play, is apparent (Vossekuil, Fein, Reddy, Borum, \& Modzeleski, 2002). This finding might reflect the low sample size $(n=41)$, and data collection methodologies and measures that varied across shooters, likely resulting in significant "noise" in the data. The low rate of school shootings makes empirical prospective studies on school shootings challenging. This is true for prospective studies that examine most types of serious criminal violence because in non-adjudicated, community-based samples, perpetration of criminal violence is so low that one obtains very small numbers of perpetrators in any one study.

Empirical studies of media violence and violent behavior more generally provide support for the hypothesis that weapon carrying may be affected by violent video game play. For example, Huesmann and Eron (1986) and Huesmann and Miller (1994) with a prospective 22-year longitudinal study, showed that males who preferred to watch more TV violence at age 8 committed more criminal violence (including violence with weapons) by age 30, based upon New York State criminal records. In a separate, 15-year longitudinal study, Huesmann, Moise-Titus, Podolski, and Eron (2003) showed that a male's amount of TV violence viewing at ages 6-9 predicted his likelihood of being convicted of a crime at ages 21-24, based upon Illinois criminal records. Exposure also predicted self-reports of committing criminally violent acts for both males and females at ages 21-24. In a study of over 1,500 adolescents 10-15 years old, Ybarra et al. (2008) found that exposure to violence in television, games, music, and the Internet were each associated with concurrently elevated odds of seriously violent behavior, although these relations were explained by other influential factors in most cases.

There are a handful of retrospective studies that have looked at exposure to all media violence, including video game violence, and how it relates to subsequent serious violent, delinquent, or criminal behavior. Boxer, Huesmann, Bushman, O'Brien, and Moceri (2009) found that retrospective reports of playing violent video games in childhood among adjudicated delinquent youth and high school students from high-risk schools in Michigan predicted self-reported serious criminal violence in later adolescence-including the use of knives and guns. In a parallel retrospective study of prisoners in Indiana, Huesmann (2013) found that playing violent video games in childhood and adolescence was reported significantly more frequently by young male prisoners who were serving time for violent than non-violent crimes.

\section{Why Exposure to Media Violence Stimulates Violent Behavior in the Observer}

Psychological theories that have emerged over the past two decades generally agree that violent behavior is caused by the convergence of multiple predisposing and precipitating factors, including both individual and situational characteristics. Among them, exposure to media violence is considered both an important precipitating factor and, when observed repeatedly, an important predisposing factor in the prediction of violent behavior. Thus, media violence has both immediate (short-term) and enduring (long-term) effects on aggressive behavior (Huesmann, 1988, 1998; Huesmann \& Kirwil, 2007; Huesmann et al., 2003).

Priming theory explains relatively short-term, underlying processes by which exposure to media violence can stimulate aggression. The logic of priming is based on cognitive and scientific perspectives that describe human memory as an associative network of scripts or schemas representing semantically related thoughts, feelings, and behavioral tendencies (Fisk \& Taylor, 1984; Huesmann, 1998). A script is an encoded sequence of behaviors and expected responses by others, while schemas are belief systems about the self, others, or the world. The priming literature suggests that violent media content can prime or activate aggressive scripts and schemas in one's memory, and these aggressive scripts and schemas can in turn increase the likelihood of subsequent hostile response 
to certain situations, especially those involving interpersonal conflicts or frustration (Bargh \& Pietromonaco, 1982). Researchers argue that such activation and processing of aggressive scripts may occur even without one's conscious awareness, "eventually mak[ing] them chronically accessible" (Bargh \& Pietromonaco, 1982; Huesmann \& Kirwil, 2007, p. 549). Media violence research offers empirical evidence that the mere presence of cues associated with violence, such as weapons, can trigger aggressive thoughts and response (Anderson, Benjamin, \& Bartholow, 1998; Berkowitz \& LePage, 1967; Josephson, 1987). Furthermore, the arousing properties of media violence can immediately transfer to other behaviors and increase the risk for aggressive behavior in the short run (Zillmann, Bryant, Comisky, \& Medoff, 1981).

Unlike priming and arousal, whose effects are relatively fleeting, observational learning theory posits specific mechanisms through which viewing violent media may increase aggression in the long-term. Observational social learning theory (Bandura, 1977) explains that human beings learn specific social behaviors directly from observing others at a very early age, imitating them, and having their behavior then reinforced. Huesmann (Huesmann, 1988, 1998; Huesmann \& Kirwil, 2007; Huesmann et al., 2003), drawing on Bandura's theorizing as well as ideas of Sears, Rau, and Alpert (1965), elaborated the idea that, through the observation of others, individuals acquire not just behaviors but whole scripts, schemas, and beliefs through inferences they make when observing others. Children can develop normative judgments about how violence can and should be expressed, as well as how the world operates more generally, based upon inferences they draw from their observation of violence. A child who is repeatedly exposed to and identifies with violent media characters who always achieve victory by means of violence may perceive the world to be a more violent place, and also may think that it is socially acceptable to resolve any encountered conflict with violence. In particular, children acquire cognitive schemas that represent "normative belief approving of aggression" and "hostile world views" that make them more likely to attribute hostility to others (Dodge \& Frame, 1982; Gerbner \& Gross, 1976; Huesmann, 1998; Huesmann \& Guerra, 1997; Huesmann \& Kirwil, 2007, pp. 547-548). Similar theoretical accounts have been advanced by Anderson and Bushman (2001) in what they denote as the "general aggression model."

These theoretical accounts explain both immediate and lasting effects of exposure to violent passive media and violent interactive media (e.g., violent video game playing), and their psychological and behavioral consequences. Many researchers argue that violence in the form of interactive media, such as electronic games, may have even stronger psycho-physiological effects than passive media, because the interactive nature reinforces violent behavior through repetition, reward, and realism (Anderson, 2004; Anderson \& Bushman, 2001; Anderson \& Huesmann, 2003; Huesmann \& Kirwil, 2007). Due to advances in computer technology, violent images in video games are becoming more common, and more vivid and realistic. These appealing features of interactive games can elicit the same or even stronger levels of emotional and physical involvement than can passive media, resulting in equal or greater degrees of identification with violent media characters, which in turn, increases the likelihood that children will mimic the violent acts of these characters. Additionally, violent video games should be equally good or even better than passive media at instilling normative judgments and world views about violence, particularly in children who are already aggressive.

\section{Why Playing Violent Video Games Would Make Weapon Carrying More Likely}

Based upon the theoretical framework described above, playing violent games in the long-term: engenders beliefs that aggression is acceptable (which should promote weapon carrying); causes violent scripts involving weapons to be encoded (which should promote weapon carrying); provokes schemas that the world is a hostile place (which would make weapon carrying more likely for self-defense); and desensitizes the player to negative emotions associated with violence and weapons (which should make it more pleasant to carry a weapon). Thus, for some adolescents who play violent games, it would be consistent with the violent scripts observed in many violent video games to carry a weapon. This behavior also would be consistent with the schemas taught by the games that the world is a hostile place (similar to Gerbner's "mean world syndrome": Gerbner, Gross, Morgan, Signorielli, \& Shanahan, 2002), and the beliefs promoted by the games that aggression is normative. These "hostile-world" effects on weapon carrying may be especially powerful for youth who are being bullied as they seek to identify what they perceive to be effective methods that will protect themselves from the bully.

\section{Hypotheses}

Because weapon carrying facilitates more violent behavior than could otherwise be expressed without a weapon, understanding factors that may increase an adolescent's likelihood of carrying a weapon is critically important. Taken together, previous empirical research and associated theory suggest that playing violent video games may increase the risk of the player behaving 
violently proactively or reactively, and that carrying a weapon facilitates such behavior. Consequently, we put forth the following hypotheses: (1) We predict that weapon carrying will be related to violent game playing by an adolescent; (2) That peer victimization will have an additive effect and also be related to weapon carrying; and (3) That these relations will persist even after taking into account other influential factors as identified above (e.g., substance use, aggression).

\section{METHODS}

\section{Participants and Procedure}

Growing up with Media is a longitudinal survey examining the associations between exposure to violent media-particularly new media (e.g., the Internet) - and violent behavior. Wave 1 data were collected in AugustSeptember 2006 with 1,586 youth-caregiver pairs; data were again collected in November 2007-January 10, 2008 [Wave 2, $(n=1,204)$ ], and August-November 2008 [Wave 3, $(n=1,157)]$. The survey protocol was reviewed and approved by the Centers for Disease Control and Prevention Institutional Review Board (IRB). At each wave, parents provided informed consent for their participation and permission for their child's participation; and children provided informed assent for their participation.

Participants were recruited through an email to randomly identified adult Harris Poll OnLine (HPOL) panel members who reported a child living in the household. Eligible adults were equally or more knowledgeable than other adults living in the same household about the youth's daily activities. Adults who were single parents were assumed to be the most knowledgeable adult in the household. Youth participants were 10-15 years old, read English, lived in the household at least $50 \%$ of the time, and had used the Internet in the last 6 months. Recruitment was balanced on youth age and biological sex.

The Wave 1 survey response rate $(31 \%)$ is consistent with well-conducted online surveys (Kaplowitz, Hadlock, \& Levine, 2004). To maximize data, respondents were invited to take part at Wave 3 irrespective of their participation at Wave 2. Response rates were $76 \%$ and $73 \%$ of baseline participants at Wave 2 and Wave 3, respectively. As shown in Table 1, youth characteristics were similar across all three waves of data collection.

On average, adult surveys lasted $5 \mathrm{~min}$ and youth surveys $21 \mathrm{~min}$. Youth received a \$20 gift certificate and caregivers a $\$ 15$ check for their participation in Waves 1 and 2; and \$25 and \$20 respectively, at Wave 3.

\section{Measures}

During each wave, participants reported on "the past 12 months" unless otherwise indicated. Questions were modified from the Aggression-Problem Behavior Frequency Scale (Dahlberg, Toal, Swahn, \& Behrens, 2005), the Monitoring the Future study (Bachman, Johnston, \& O'Malley, 2001), the Adolescent Health study (Udry, 1996), the Youth Risk Behavior Survey (YRBS); (Centers for Disease Control and Prevention, 2008), the Juvenile Victimization Questionnaire (Hamby, Finkelhor, Ormrod, \& Turner, 2004), and the Youth Internet Safety Surveys (Finkelhor, Mitchell, \& Wolak, 2000; Wolak, Mitchell, and Finkelhor, 2006).

Main outcome and predictor variables. Weapon carrying was measured with a dichotomous (yes/no) question based upon an item in the YRBS (Centers for Disease Control and Prevention, 2008): "Thinking about the last month you were in school, on how many days did you carry a weapon, like a gun, knife or club, to school?" A follow-up question was asked to determine which specific weapons were brought to school in the past month.

Exposure to violence in game play. Youth were asked the number of days in an average week they played video and computer games; and Internet games. Youth who reported playing either video or computer, and/or Internet games at least 1 day in an average week (in the beginning of the survey) were asked about the level of exposure to violence in game play (in the middle of the survey, about 10 min later) by asking (Windle et al., 2004): "When you play video, computer or Internet games, how many show physical fighting, shooting, or killing?" Response options were: none/almost none of the time, sometimes, most of the time, almost all/all of the time. Because only four options were allowed for the response, the item could not be used as a continuous variable (Jamieson, 2004). In this case, the top three categories were combined to allow for stable estimates in multivariable models. The resulting dichotomous variable compared youth who played no or almost no games depicting violence with youth who played at least some violence in the past 12 months.

Peer victimization was measured by a sum of five items (Bachman et al., 2001; Dahlberg et al., 2005; Finkelhor et al., 2000): (1) Someone did not let me in their group because they were mad at me; (2) Someone pulled a knife or gun on me; (3) Someone stole something from mefor example, a backpack, wallet, lunch money, book, clothing, running shoes, bike, or anything else; (4) Another person or group attacked me-for example, an attack at home, at someone else's home, at school, at a store, in a car, on the street, at the movies, at a park, or anywhere else; and (5) Someone spread a rumor about me, whether it was true or not. Responses were captured on a 6 point Likert scale: 0 (never)- 5 (every day/almost every day) (range: $0-25$; Cronbach's alpha $=.71-.76$ across the three waves). Frequent and intense peer victimization was operationalized with a binary indicator (i.e., scores $1 S D$ above the mean and higher, vs. lower) to 
TABLE 1. A Comparison of Demographic Characteristics of Youth Across the Three Data Collection Waves

\begin{tabular}{|c|c|c|c|c|}
\hline & Wave $1(n=1,581)$ & Wave $2(n=1,195)$ & Wave $3(n=1,150)$ & \\
\hline Youth Demographic Characteristics & $\%(n)$ & $\%(n)$ & $\%(n)$ & $P$-value \\
\hline Male sex & $51.1 \%(794)$ & $52.7 \%(604)$ & $52.3 \%(582)$ & .23 \\
\hline Age (years) & & & & $<.001$ \\
\hline 9 & $0.5 \%(7)$ & $0.0 \%(0)$ & $0.0 \%(0)$ & \\
\hline 10 & $15.8 \%(273)$ & $0.5 \%(4)$ & $0.0 \%(0)$ & \\
\hline 11 & $13.5 \%(243)$ & $14.3 \%(187)$ & $1.4 \%(21)$ & \\
\hline 12 & $17.5 \%(265)$ & $12.6 \%(189)$ & $12.3 \%(174)$ & \\
\hline 13 & $15.3 \%(241)$ & $16.4 \%(206)$ & $14.2 \%(195)$ & \\
\hline 14 & $20.3 \%(277)$ & $15.3 \%(181)$ & $18.7 \%(200)$ & \\
\hline 15 & $17.0 \%(274)$ & $20.4 \%(189)$ & $14.4 \%(163)$ & \\
\hline 16 & $0.1 \%$ & $17.9 \%(206)$ & $21.6 \%(197)$ & \\
\hline 17 & $0.0 \%(0)$ & $2.7 \%(33)$ & $16.4 \%(194)$ & \\
\hline 18 & $0.0 \%(0)$ & $0.0 \%(0)$ & $1.0 \%(6)$ & \\
\hline Hispanic ethnicity & $16.6 \%(205)$ & $15.7 \%(144)$ & $15.8 \%(137)$ & .69 \\
\hline Race & & & & .26 \\
\hline White & $71.4 \%(1,153)$ & $75.6 \%(899)$ & $72.1 \%(853)$ & \\
\hline Black/African American & $13.6 \%(217)$ & $11.1 \%(147)$ & $14.0 \%(149)$ & \\
\hline Mixed racial background & $8.9 \%(114)$ & $7.7 \%(80)$ & $8.5 \%(83)$ & \\
\hline Other race & $6.1 \%(97)$ & $5.6 \%(69)$ & $5.5 \%(65)$ & \\
\hline \multicolumn{5}{|l|}{ Main variables of interest } \\
\hline Weapon carrying & $1.6 \%(25)$ & $1.5 \%(21)$ & $0.9 \%(16)$ & .50 \\
\hline Violent game play & $70.5 \%(973)$ & $65.5 \%(710)$ & $67.6 \%(697)$ & .08 \\
\hline Frequent and intense peer victimization & $15.2 \%(247)$ & $14.0 \%(157)$ & $10.0 \%(121)$ & .007 \\
\hline
\end{tabular}

Note. Percentages are weighted; sample $n$ 's are not.

increase the interpretive value of the findings as opposed to an interpretation based upon incremental changes in score value.

\section{Potential confounders}

Media. A factor score was estimated to reflect the levels of other violent media exposure (i.e., physical fighting, shooting, or killing, as described above) that were reported across four types of non-gaming media: music, television, websites showing real people, and websites showing cartoon people (Cronbach's alpha $=$ $.65-.66$ across the three waves).

Youth were asked on how many days in a typical week they played computer or video games; and they played Internet games; and for how long they played these games in a typical day. [Note that these questions were crafted in 2006 when convergence of technology was at a different stage, which is why computer games were asked with video games, rather than with Internet games.] A factor score was estimated based upon these four items to reflect intensity and frequency of game play (Cronbach's alpha $=.81-.84$, depending on wave).

Externalizing behaviors. Aggressive behavior was measured as the sum of the overall frequency of engaging in six physically or verbally, direct or indirect, aggressive behaviors (Bachman et al., 2001; Dahlberg et al., 2005): (1) Shoved, or pushed, or hit or slapped another person your age; (2) threatened to hurt a teacher; (3) been in a fight in which someone including yourself was hit; (4) gotten into a fight where a group of your friends were against another group of people; (5) not let another person your age be in your group anymore because you were mad at them; and (6) spread a rumor about someone, whether it was true or not (range: 0-30; Cronbach's alpha $=.77-.79$, depending on Wave).

Mirroring the symptoms of conduct disorder (American Psychiatric Association, 2000), youth were asked how often they engaged in nine non-personal delinquent behaviors: (1) Banged up or damaged something that did not belong to you; (2) started a fire on purpose, where you wanted something to get damaged or destroyed; (3) broken into someone else's house, building or car; (4) lied to someone to get something that you wanted, or to get someone to do you a favor, or to get out of doing something you did not want to do; (5) taken something that was valuable, like shoplifting or using someone else's credit card, when no one was looking; (6) stayed out at night even though you knew your parents would not want you to; (7) run away from home and stayed away overnight; (8) ditched/skipped school; and (9) hurt an animal on purpose, like cutting off its tail, hitting or kicking it, or killing it for fun. Item \#1 was based upon previous studies (Finkelhor et al., 2000; Wolak et al., 2006); all other items were created for GuwM based upon the Diagnostic and Statistical Manual (American Psychiatric Association, 2000). Responses were captured on a 5-point Likert scale and summed to create a "delinquency score," with higher scores reflecting greater delinquency (range = 0-45; Cronbach's alpha ranged between .74 and .87 , depending on wave). 
Youth also were asked how frequently they engaged in five different seriously violent behaviors: (1) Threatened someone with a weapon (gun, knife, club, etc.); (2) hurt someone badly enough that they needed to be treated by a doctor or nurse; (3) used a knife or gun or some other kind of weapon like a bat to get something from someone else; (4) kissed, touched, or done anything sexual with another person when that person did not want you to; and (5) stabbed or shot someone. Items \#1-3, and 5 were from previous studies (Bachman et al., 2001; Dahlberg et al., 2005); \#4 was created for GuwM. Responses were captured on a 5-point Likert scale and summed to create a "violence score," with higher scores reflecting greater violence (range: 0-25; Cronbach's alpha ranged between .88 and .95 , depending on the wave).

Substance use was measured using a factor score reflecting alcohol use, marijuana use, inhalant use, and use of all other drugs ever in the past year for all waves (Centers for Disease Control and Prevention, 2008). Cigarette use also was included in Waves 2 and 3. Internal consistency was acceptable across waves (Cronbach's alpha ranged between .66 and .73).

Exposure to violence in real life. Three separate (dichotomous) items were asked to measure exposure to violence in the community and exposure to caregiver spousal abuse (Hamby et al., 2004): (1) Seen someone steal something from a home, a store, a car, or anywhere else? Things like a TV, stereo, car, or anything else? (2) Been in a place in real life where you could see or hear people being shot, bombs going off, or street riots? and (3) Seen one of your parents get hit, slapped, punched, or beat up by your other parent, or their boyfriend or girlfriend? Each was entered singly into the multivariate models.

Caregiver-child relationships. Youth were asked to think about the parent or guardian in their home who knows the most about them. Caregiver monitoring was then queried with two questions (Finkelhor et al., 2000): (1) How often does this person know where you are when you are not at home; and (2) does this person know who you are with when you are not at home. Response options were captured on a 5-point Likert scale ranging from never to all of the time. Responses on the two variables were summed to create a score for parental monitoring, with higher scores reflecting poorer monitoring (range: $2-10$; correlation $=$ .81-.83, depending on Wave).

In the same survey section, emotional bond was measured with three questions (Finkelhor et al., 2000): (1) How well would you say you and this person get along? (2) How often do you feel that this adult trusts you? and (3) How often if you were in trouble or were sad would you discuss it with this person? Responses were summed to create a score of emotional bond (range: 3-
15), which was then dichotomized because of indications of collinearity with other variables to compare youth with scores $2 S D$ s above the mean or higher, versus lower. Internal consistency was acceptable (Cronbach's alpha ranged from .62 to .71 , depending on wave).

A propensity to respond to stimuli with anger was measured with the 10-item trait subscale of the State-Trait Anger Expression Inventory (STAXI); (Forgays, Forgays, \& Speilberger, 1997; Spielberger \& Reheiser, 2004). Youth were asked to indicate how often each statement was true for them, such as: I fee grouchy; I get mad; and I get angry quickly. Items were scored on a 3point scale ranging from: "hardly ever true" to "often true" and summed to create a score that reflected one's propensity to respond to stimuli with anger (range: 0-30; Cronbach's alpha ranged from .85 to .88 , depending on wave). Responses were dichotomized to reflect scores 2 $S D$ s above the mean versus lower to address issues of inter-collinearity.

Academic indicators. Youth were asked "What kind of grades do you get in school." Eight options were offered, ranging from "Mostly As" to "Mostly Ds and lower." A dichotomous variable was created to reflect youth with grades $2 S D$ s below the mean (mostly Cs) and lower versus all other youth (mostly Bs and Cs, and better). Youth also were asked the number of detentions and/or suspensions that they had had in the past year.

Peers. Delinquent peers was measured as a continuous variable of the number of "close friends [who] have been arrested or done things that could get them in trouble with the police" (Office of Juvenile Justice and Delinquency Prevention, 1998).

Demographic characteristics. Caregivers reported annual household income, youth biological sex, and youth age. Youth self-reported their race and ethnicity.

\section{Data Cleaning and Analyses}

HPOL data are comparable to data that have been obtained from random telephone samples of adult populations once appropriate sample weights are applied (Schonlau et al., 2004). Data were weighted statistically to reflect the population of adults with children ages 10 15 -years old in the United States according to adult age, sex, race/ethnicity, region, education, household income, and child age and sex (Bureau of Labor Statistics \& Bureau of the Census, 2006). Survey sampling weights also adjusted for adult respondents' self-selection into the HPOL as well as account for differential participation over time (Schonlau et al., 2004). Adult caregivers were the target of the weighting because they were the individual who was initially recruited into the sample.

Youth were required to answer each question in order to move forward in the survey. "Decline to answer" 
responses were imputed using the "impute" command in Stata (StataCorp, 2009). To reduce the likelihood of imputing data from truly non-responsive participants, youth respondents were required to have valid data for at least $80 \%$ of the survey questions asked of all youth to be included in the analytic sample. Five respondents did not meet this criterion and were dropped from the Wave 1, nine were dropped from the Wave 2, and seven from the Wave 3 samples.

Birthday was added as a question at Wave 4. Recent data cleaning suggests that seven youth were probably 9 years old instead of 10 years old, and one youth was 16 years old instead of 15 years old at Wave 1 . To maximize the amount of data, and because caregivers did not know the eligibility criteria (and were, therefore, unlikely to have misreported their child's age purposefully), these youth are included in the analyses.

\section{Identifying the Analytical Sample}

Given that the aim of the paper is to understand the influence that content in video games may have on behavior, youth who were home schooled or out of school (64 at Wave 1; 58 at Wave 2; 58 at Wave 3) and/ or youth who did not report the exposure of interest (i.e., video, computer, or Internet game play at least one day in an average week: 100 at Wave 1; 122 at Wave 2; 146 at Wave 3) were excluded. Note that in some cases youth were excluded for both reasons. Youth who do not play games do not have exposure to any type of game content. Their inclusion would therefore confound the measure. Excluding them allows us to isolate the influence that the content has on behavior, among youth who play games. Their inclusion could also potentially introduce cell instability in the model due to the small number of weapon-carrying youth. Thus, 3,397 observations from 1,489 individuals $(1,421$ respondents at Wave 1; 1,024 respondents at Wave 2; and 952 respondents at Wave 3) were included in the analyses.

As shown in Table 2, youth who played games in a typical week and attended public or private school were similar to youth who did not in terms of race, ethnicity, and weapon carrying. They were significantly more likely to be male and younger, however. Given that one of the criteria for inclusion in the analytical sample was playing games, it is not surprising that excluded youth were less likely to play games.

\section{Data Analyses}

Because few youth reported carrying a weapon to school in the past month across the three waves of data, it was impossible to estimate a stable, longitudinal model that also took into account important covariates as identified above. Thus, a marginal model with generalized estimating equations (GEE) was used to maximize the available data by estimating the population-average odds of weapon carrying in the past month as a function of violent video and computer game play in the past 12 months, while accounting for clustering in the data within person over time. An exchangeable correlation was assumed. Resulting odds ratios represent the average odds observed over the 3 years' of observations.

An interaction between violent game play and peer victimization was tested to determine whether youth who reported both were especially likely to report weapon carrying. Next, a parsimonious logistic regression model was identified so that the most influential characteristics would be apparent. The model was built using a forward stepwise methodology: variables were added one-by-one based upon significant contribution to the model (Wald test of $P<.10$ or $P$-value of variable $P<.10$; or OR $>=2.0$ and marginal significance). Game play and peer victimization were retained in the model irrespective of statistical significance because they were the main and secondary predictors of interest in the current investigation. Sex was retained irrespective of statistical significance because of the noted difference in violent game play (see below). Survey characteristics (self-reported honesty, being monitored during the survey, and wave of data collection) also were retained irrespective of statistical significance. Analyses were conducted using Stata 11 (StataCorp, 2009). As such, percentages are weighted whereas the subsample sizes noted are actual.

\section{RESULTS}

Among youth who played video or computer (including Internet) games in the past year and were attending a public or private school in the United States at some time over the three waves of data collection, $1.4 \%(n=53)$ reported carrying at least one weapon to school in the past month: $83 \%(n=41)$ of weapon carriers reported carrying a knife; $33 \%(n=11)$ a gun; $24 \%(n=8)$ a bat, club or pipe; and $13 \%(n=11)$ some other type of weapon (multiple responses were allowed).

Thirty-one percent of youth $(n=1,162)$ reported that almost none or none of the games that they played depicted violence. Although the sample was relatively equal by biological sex ( $56 \%$ male, $44 \%$ female), $87 \%$ of male youth versus $47 \%$ of female youth reported playing at least some games that depicted violence $(P<.001)$.

\section{The Unadjusted Relation Between Violent Games and Weapon Carrying}

On average, $24 \%$ of youth who reported carrying a weapon to school also said that "almost all" or "all" of the games they played depicted violence, compared to $11 \%$ 
TABLE 2. A Comparison of Characteristics of Youth Included and Excluded From the Analytical Sample ( $n=3,926$ Observations Across 1,583 Youth)

\begin{tabular}{|c|c|c|c|}
\hline & Excluded $(n=529)$ & Analytical Sample $(n=3,397)$ & \\
\hline Youth Demographic Characteristics & $\%(n)$ & $\%(n)$ & $P$-value \\
\hline Male sex & $29.1 \%(163)$ & $55.8 \%(1,817)$ & $<.001$ \\
\hline Age (mean: SE, in years) & $14.4(0.15)$ & $13.4(0.06)$ & $<.001$ \\
\hline Hispanic ethnicity & $17.3 \%(81)$ & $15.9 \%(405)$ & .69 \\
\hline Race & & & .33 \\
\hline White & $73.1 \%(393)$ & $72.8 \%(2,512)$ & \\
\hline Black/African American & $10.8 \%(54)$ & $13.3 \%(459)$ & \\
\hline Mixed racial background & $11.9 \%(46)$ & $7.8 \%(231)$ & \\
\hline Other race & $4.2 \%(36)$ & $6.0 \%(195)$ & \\
\hline \multicolumn{4}{|l|}{ Main variables of interest } \\
\hline Weapon carrying & $1.2 \%(9)$ & $1.4 \%(53)$ & .76 \\
\hline Violent game play & $52.5 \%(145)$ & $69.3 \%(2,235)$ & .001 \\
\hline Frequent and intense peer victimization & $11.8 \%(56)$ & $13.6 \%(469)$ & .58 \\
\hline
\end{tabular}

Note. Because youth needed to both attend public or private school and play games; some youth who were excluded reported playing violent games (available from authors upon request).

of non-weapon carrying youth. As shown in Figure 1, the amount of violent game play differed significantly between weapon- and non-weapon carrying youth for female game players $(P<.001)$ and was marginally significantly different for males $(P=.10)$.

Over the 3 -year period, $7 \%(n=33)$ of youth who were frequently and intensely targeted by peer victimization (i.e., those who reported levels of victimization $1 S D$ above the mean or higher) reported carrying a weapon in the past month to school compared to $0.6 \%(n=20)$ of all other youth (Design-based $F(1,1485)=53.6, P<.001)$.

As shown in Table 3, almost all characteristics posited to be associated with weapon carrying were statistically significant at the bivariate level. Notably, violent game

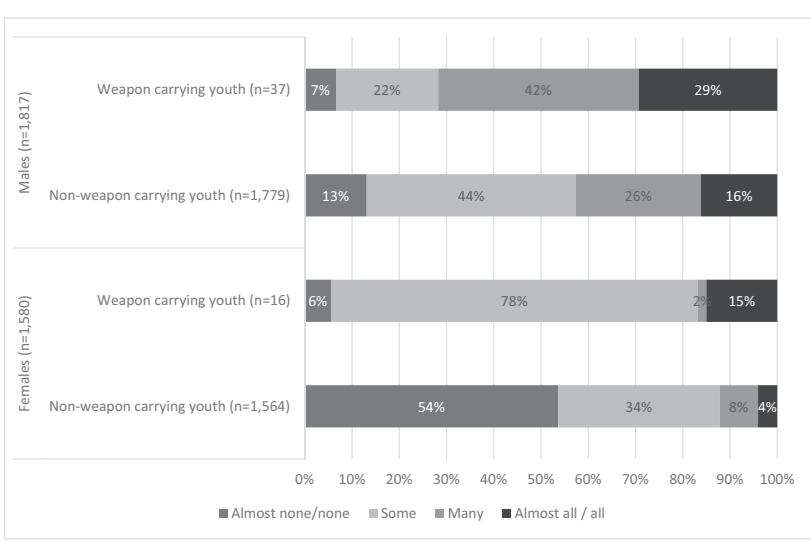

Fig. 1. A comparison of the amount of violence in game played among weapon and non-weapon carrying youth based upon the self-report of violent game playing among school-attending youth who have played video, computer, or internet games in the past 12 months. Females: Design-based $F(2.19,1576.80)=9.3, P=<.001$. Males: Design-based $F(2.91,2221.91)=2.1, P=.10$. play was associated with sevenfold, and frequent and intense peer victimization, 11-fold increased odds of also carrying a weapon to school in the last month. Poor academic performance and amount of game time, as well as all demographic characteristics, were exceptions and not significantly associated with weapon carrying.

\section{The Relation Between Violent Games and Weapon Carrying, Adjusted for Covariates}

Compared to $7 \%$ of youth who were bullied and played violent games, $3 \%$ of youth who were bullied and played non-violent games, $0.9 \%$ of youth who played violent games and were not bullied, and $0 \%$ of youth who neither played violent games nor were bullied reported carrying a weapon to school in the past month (Design-based F(3.0, $4419.5)=21.4 ; P<.001)$. Although this was strongly suggestive of effect modification, lack of youth in the reference group reporting weapon carrying prevented further investigation. As such, each characteristics was entered into the model singly.

The combined association of violent video game play and peer victimization with weapon carrying, after adjusting for biological sex and survey process measures, is shown in Table 4, Model 1. When estimating the saturated model that included all variables of interest, the continuous measure of caregiver-child emotional relationships and age had variance inflation factors over the recommended cut-off of 10.0 (11.4 and 16.0, respectively). Once the caregiver-child relationship was dichotomized to reflect youth who reported extremely poor relationships (i.e., $2 S D$ above the mean and higher), concerns about inter-collinearity were generally unsupported (mean $\mathrm{VIF}=2.33$, Range: 1.08-12.61; see Model 2, Table 4). 
TABLE 3. Prevalence Rates and Unadjusted Odds Ratios for Youth Characteristics Given Self-Reported Weapon Carrying at School in the Past Month Among School-Attending Youth Who Have Played Video, Computer, or Internet Games in the Past 12 Months ( $n=3,397$ Observations From 1,489 Youth)

\begin{tabular}{|c|c|c|c|c|c|}
\hline \multirow[b]{2}{*}{ Youth Characteristics } & \multicolumn{2}{|c|}{ No Weapon Carrying $(n=3,344)$} & \multicolumn{2}{|c|}{ Weapon Carrying ( $n=53$ ) } & \multirow[b]{2}{*}{ OR $(95 \% \mathrm{CI})$} \\
\hline & $\%(n)$ & Mean (SE) & $\%(n)$ & Mean (SE) & \\
\hline Violent game play & $68.9 \%(2,185)$ & & $93.8 \%(50)$ & & $6.78(1.55,29.59)$ \\
\hline Frequent and intense peer victimization & $12.9 \%(436)$ & & $62.5 \%(33)$ & & $11.30(5.03,25.37)$ \\
\hline \multicolumn{6}{|l|}{ Potential confounders } \\
\hline \multicolumn{6}{|l|}{ Media exposure } \\
\hline Other violent media exposure (factor score) & & $0.03(0.02)$ & & $1.4(0.23)$ & $3.26(2.34,4.54)$ \\
\hline Amount of game use (factor score) & & $0.1(0.03)$ & & $0.3(0.19)$ & $1.27(0.77,2.09)$ \\
\hline \multicolumn{6}{|l|}{ Externalizing behaviors } \\
\hline High propensity to respond to stimuli with anger & $4.1 \%(110)$ & & $23.8 \%(12)$ & & $7.39(2.88,18.98)$ \\
\hline Seriously violent behavior (sum) & & $0.11(0.02)$ & & $5.3(1.39)$ & $1.47(1.26,1.71)$ \\
\hline Amount of substance use (factor score) & & $0.03(0.03)$ & & $1.4(0.48)$ & $1.60(1.37,1.87)$ \\
\hline Aggressive behavior (sum) & & $1.8(0.09)$ & & $11.0(1.76)$ & $1.33(1.25,1.42)$ \\
\hline Delinquent behavior (sum) & & $1.8(0.10)$ & & $10.8(1.99)$ & $1.25(1.17,1.34)$ \\
\hline Number of delinquent peers & & $0.6(0.06)$ & & $2.5(0.50)$ & $1.19(1.11,1.28)$ \\
\hline \multicolumn{6}{|l|}{ School behaviors } \\
\hline Number of detentions/suspensions & & $0.9(0.10)$ & & $2.4(0.76)$ & $1.06(1.02,1.09)$ \\
\hline Poor academic performance & $11.6 \%(360)$ & & $14.4 \%(13)$ & & $1.29(0.53,3.16)$ \\
\hline \multicolumn{6}{|l|}{ Caregiver-child relationships } \\
\hline Extremely poor caregiver-child emotional bond & $4.3 \%(125)$ & & $18.8 \%(15)$ & & $5.11(2.21,11.82)$ \\
\hline Poor parental monitoring (sum) & & $3.1(0.05)$ & & $4.5(0.41)$ & $1.48(1.26,1.74)$ \\
\hline \multicolumn{6}{|l|}{ Exposure to community violence } \\
\hline Witnessing a robbery & $17.2 \%(547)$ & & $49.3 \%(30)$ & & $4.66(2.10,10.36)$ \\
\hline Hearing gun shots & $6.6 \%(191)$ & & $19.8 \%(15)$ & & $3.48(1.52,7.96)$ \\
\hline Witnessing caregiver spousal abuse & $6.7 \%(206)$ & & $17.9 \%(11)$ & & $3.03(1.23,7.42)$ \\
\hline \multicolumn{6}{|l|}{ Demographic characteristics } \\
\hline Male sex & $55.7 \%(1,780)$ & & $64.1 \%(37)$ & & $1.42(0.60,3.38)$ \\
\hline Age (years) & & $13.4(0.06)$ & & $13.6(0.48)$ & $1.04(0.80,1.35)$ \\
\hline Low household income ( $<\$ 25,000$ vs. higher) & $22.3 \%(732)$ & & $18.5 \%(12)$ & & $0.80(0.26,2.40)$ \\
\hline Hispanic ethnicity & $15.8 \%(398)$ & & $25.4 \%(7)$ & & $1.82(0.64,5.14)$ \\
\hline \multicolumn{6}{|l|}{ Race } \\
\hline White & $72.9 \%(2,480)$ & & $65.6 \%(32)$ & & $1.0(\mathrm{RG})$ \\
\hline Black/African American & $13.3 \%(450)$ & & $11.6 \%(9)$ & & $0.97(0.26,3.55)$ \\
\hline Mixed race & $7.8 \%(225)$ & & $9.9 \%(6)$ & & $1.41(0.41,4.85)$ \\
\hline Other race & $5.9 \%(189)$ & & $12.8 \%(6)$ & & $2.41(0.65,8.94)$ \\
\hline \multicolumn{6}{|l|}{ Survey process measures } \\
\hline Self-reported dishonesty in answering survey questions & $3.5 \%(109)$ & & $7.0 \%(4)$ & & $2.04(0.52,7.97)$ \\
\hline Not alone when completing the survey & $41.1 \%(1,461)$ & & $49.8 \%(26)$ & & $1.42(0.66,3.07)$ \\
\hline
\end{tabular}

Note. OR, odds ratio; CI, confidence interval; RG, reference group.

Fifteen variables were dropped in the forward stepwise model building that resulted in the parsimonious model of influential characteristics related to weapon carrying. This simpler model (Model 3, Table 4) was statistically comparable to the saturated model $\left(\chi^{2}\right.$ $(17)=20.20, P=.26)$. Estimates suggested that, among otherwise similar youth who played games and also attended a private or public school in the past year, the relative odds of carrying a weapon to school was over four times higher for youth who played at least some games depicting violence compared to youth who played games with no violent content. Exposure to violence in other media, substance use, and aggressive behavior also were associated with increased odds of carrying a weapon to school in the past month. A propensity to respond to stimuli with anger was borderline significant. Peer victimization was not significantly associated with weapon carrying once other factors were taken into account.

The parsimonious model was rerun with non-game players included in the sample (3,746 observations from 1,535 youth). Similar results were observed: Youth who played at least some games with violent content were significantly more likely than those who played games with none or almost no violent content to report recent weapon carrying $(\mathrm{aOR}=5.10,95 \% \mathrm{CI}: 1.59,16.37)$. The odds of weapon carrying also were elevated, but not statistically significantly so, for non-game players compared to game players who reported none or almost none of the games they played depicted violent content 
TABLE 4. Results of Multivariable, Population-Average Logistic Regression Models Predicting the Odds of Weapon Carrying to School in the Past Month Based Upon the Self-Report of Violent Game Playing Among School-Attending Youth Who Have Played Video, Computer, or Internet Games in the Past 12 Months (3,397 Observations From 1,489 Youth)

\begin{tabular}{|c|c|c|c|}
\hline & Model 1: Games and Victimization & Model 2: Saturated Model & Model 3: Parsimonious Model \\
\hline Youth Characteristics & aOR $(95 \% \mathrm{CI})$ & aOR $(95 \% \mathrm{CI})$ & aOR $(95 \% \mathrm{CI})$ \\
\hline Violent game play & $4.63(0.93,23.05)$ & $6.41(1.10,37.37)$ & $4.84(1.44,16.23)$ \\
\hline Frequent and intense peer victimization & $9.63(4.23,21.93)$ & $1.76(0.80,3.89)$ & $1.26(0.53,3.00)$ \\
\hline \multicolumn{4}{|l|}{ Potential confounders } \\
\hline \multicolumn{4}{|l|}{ Media exposure } \\
\hline Other violent media exposure & & $2.53(1.20,5.34)$ & $2.14(1.28,3.56)$ \\
\hline Amount of game use & & $0.64(0.36,1.14)$ & \\
\hline \multicolumn{4}{|l|}{ Externalizing behaviors } \\
\hline High propensity to respond to stimuli with anger & & $3.13(0.89,11.06)$ & $2.19(0.74,6.48)$ \\
\hline Seriously violent behavior (sum) & & $1.14(0.90,1.46)$ & \\
\hline Amount of substance use (factor score) & & $1.57(1.26,1.95)$ & $1.60(1.29,1.98)$ \\
\hline Aggressive behavior (sum) & & $1.12(0.96,1.32)$ & $1.24(1.14,1.34)$ \\
\hline Delinquent behavior (sum) & & $1.03(0.89,1.20)$ & \\
\hline Number of delinquent peers & & $0.97(0.85,1.11)$ & \\
\hline \multicolumn{4}{|l|}{ School behaviors } \\
\hline Number of detentions/suspensions & & $1.00(0.94,1.08)$ & \\
\hline Poor academic performance & & $0.51(0.15,1.68)$ & \\
\hline \multicolumn{4}{|l|}{ Caregiver-child relationships } \\
\hline Extremely poor caregiver-child emotional bond & & $0.88(0.28,2.77)$ & \\
\hline Poor parental monitoring & & $1.05(0.84,1.32)$ & \\
\hline \multicolumn{4}{|l|}{ Exposure to community violence } \\
\hline Witnessing a robbery & & $0.82(0.33,2.05)$ & \\
\hline Hearing gun shots & & $0.76(0.32,1.78)$ & \\
\hline Witnessing caregiver spousal abuse & & $1.07(0.33,3.44)$ & \\
\hline \multicolumn{4}{|l|}{ Demographic characteristics } \\
\hline Male sex & $1.22(0.45,3.30)$ & $1.00(0.25,3.97)$ & $0.89(0.31,2.59)$ \\
\hline Age (years) & & $1.05(0.67,1.62)$ & \\
\hline Low household income ( $<\$ 25,000$ vs. higher) & & $0.85(0.22,3.34)$ & \\
\hline Hispanic ethnicity & & $1.58(0.51,4.90)$ & \\
\hline \multicolumn{4}{|l|}{ Race } \\
\hline White & & $1.0(\mathrm{RG})$ & \\
\hline Black/African American & & $1.34(0.18,9.79)$ & \\
\hline Mixed race & & $0.84(0.18,4.04)$ & \\
\hline Other race & & $2.11(0.26,16.96)$ & \\
\hline \multicolumn{4}{|l|}{ Survey process measures } \\
\hline Self-reported dishonesty & $1.39(0.35,5.44)$ & $0.36(0.06,2.16)$ & $0.43(0.09,2.09)$ \\
\hline Not alone when Self-reported & $1.38(0.61,3.13)$ & $2.79(0.92,8.50)$ & $2.55(1.15,5.64)$ \\
\hline \multicolumn{4}{|l|}{ Wave } \\
\hline Wave 1 & $1.0(\mathrm{RG})$ & $1.0(\mathrm{RG})$ & $1.0(\mathrm{RG})$ \\
\hline Wave 2 & $1.26(0.52,3.04)$ & $1.33(0.33,5.27)$ & $1.25(0.45,3.50)$ \\
\hline Wave 3 & $0.67(0.21,2.08)$ & $0.40(0.10,1.69)$ & $0.39(0.06,2.51)$ \\
\hline
\end{tabular}

Note. Potential confounders not shown in Model 3 were dropped from the saturated model due to non-significance.

aOR, adjusted odds ratio; RG, reference group. CI, confidence interval.

$(\mathrm{aOR}=3.67,95 \%$ CI: $0.35,38.11)$. The wide confidence interval noted for non-game players is likely to be partly due to the relatively small sample size of non-players (247 observations) compared to players of non-violent games (1,222 observations) and violent games (2,277 observations).

\section{DISCUSSION}

Based upon prior research and theorizing (Anderson \& Bushman, 2001; Bandura, 1977; Dodge \& Frame, 1982;
Huesmann, 1998; Huesmann \& Kirwil, 2007), we posited that weapon carrying was more likely to be reported by youth who play violent games because playing violent games engenders beliefs that aggression is acceptable; stimulates the encoding of violent scripts involving weapons and schemas that the world is a hostile place; and desensitizes the adolescent to negative emotions associated with violence and weapons. Consistent with these hypotheses, among youth 9-18 years of age who play video, computer, and Internet games and attend public or private schools in the United States, we 
found that self-reports of violent game play in the past year were associated with significantly higher odds of concurrently reporting carrying a weapon to school in the past month. This association remained even when known risk factors for weapon carrying (e.g., aggressive behavior, substance use) were considered. The current findings add to the growing literature suggesting that violent video and computer games may have a facilitating impact on violent adolescent behavior for some youth (Anderson, 2004; Anderson et al., 2010; Huesmann et al., 2003; Huesmann \& Taylor, 2006; Ybarra et al., 2008).

Youth who are bullied (Nansel et al., 2003) may feel the need for self-protection (Sheley \& Wright, 1993), and the "Hostile-world" perceptions that violent games engender (Gerbner et al., 2002) may lead such youth to identify weapon-carrying as a particularly effective method that they could use to protect themselves from the bully. We therefore posited that weapon carrying would be reported more frequently by youth who were bullied, and that youth who both played violent games and were bullied would be especially likely to carry weapons. Our findings support this hypothesis: indeed $7 \%$ of youth who were victimized and played violent games in our study had brought weapons to school in the past month, whereas none of youth who were neither victimized nor played violent games had. This relation was so substantial that we were unable to examine whether other factors affect this observed difference. When we examined victimization by peers separately, however, we found that youth who had been victimized by peers were more likely to report weapon carrying, independently of playing violent video games. This relation was explained by concurrent reports of substance use and aggressive behavior, which suggests that the latter behaviors may stimulate both victimization and weapon carrying. Taken together, these findings suggest that not all youth who are bullied will carry weapons to school. Nonetheless, youth who also play violent games, are also struggling with substance use, and have problems with aggression may be more likely to respond to victimization with weapon carrying. This highlights the importance of intervening when bullying and other peer aggression is noted in the school environment; and also for making sure that youth have adequate and easy access to non-violent solutions, such as caring adults and assertive bystanders.

The aim of the current study is not to vilify games, but rather to understand the potential influence that the content in games might have on behavior. Indeed, pro-social games seem to have a facilitating impact on healthy behaviors (Baranowski, Buday, Thompson, \& Baranowski, 2008; Greitemeyer, Osswald, \& Brauer, 2010). Moreover, playing non-violent games is not uncommon: $32 \%$ of non-weapon carrying youth in the current study report that none or almost none of the games they played showed shooting, fighting, or killing. Mental health professionals and others working with youth should assess their video game consumption and exposure to violence game content. They also should assure caregivers who worry that it is impossible to affect change for their children (e.g., because "everyone" plays violent games), that if one in three youth are playing mostly non-violent games, a reduction in violent game exposure for their children is an attainable goal.

It is possible that youth who attend to the violent content and, therefore, are better able to accurately report the amount of violence in their game play also are more likely to carry weapons to school; whereas youth who play equally violent games who pay less attention to the violent content report lower exposure to violent content and also are less likely to carry weapons to school. This is why it is an important strength of the current study that the measure of violent game content is specific, concrete, and behaviorally focused. Instead of asking youth to determine how much of their games were "violent," they were asked to determine how many game characters engaged in shooting, fighting, or killing behavior.

Similar to previous studies (Brener et al., 2004; Cotten et al., 1994; DuRant et al., 1999; Nansel et al., 2003; Webster et al., 1993), several other factors appear to be related to weapon carrying, specifically substance use, exposure to violent content in other media, and aggressive behavior. Typically referred to as "Jessor's Theory of Problem Behavior," a number of studies have found that, although problem behaviors may seem disparate in typology (e.g., sexual behavior and cigarette smoking), they are interrelated and co-vary (Donovan, 1996; Donovan, Jessor, \& Costa, 1988; Gillmore, Spencer, Larson, Tran, \& Gilchrist, 1998; Jessor, 1987; Moran \& Vinovskis, 1994). More recent work has broadened the spectrum of problem behavior from substance use, delinquency, and early sexual intercourse to also include health-related behaviors such as unhealthy eating, and school behavior such as truancy and dropout (Jessor, 1998). As with other externalizing behaviors that deviate from social or legal norms, weapon carrying appears to coexist with these other problem behaviors for some youth. It seems then, that weapon carrying could also be included in the rubric of "Problem Behavior."

Previous studies (Brener et al., 2004; DuRant et al., 1999; Nansel et al., 2003) report boys are more likely than girls to carry weapons. Although three in five weapon carriers in the current study are boys, sex is not a significant predictor of weapon carrying. This might be because of the small sample size and lack of power to detect a difference. It might also be because the analyses examine the effect of violent game play and, therefore, focus on youth who play video and computer games. 
Violent game play is gendered: Boys are much more likely to play than girls (Anderson et al., 2010). Perhaps girls who play violent games are generally more aggressive than girls who do not play games. If true, then it may be that females who carry weapons and do not play games have other influential factors that better contextualize their behavior. Because of the low numbers of weapon carrying youth, we did not stratify the sample to examine potential differences in characteristics predicting weapon carrying by biological sex. Future research should focus on this important area.

It is important to note that the frequency of weapon carrying in the current study ( $1.4 \%$ across waves) is lower than that reported in the 2005 national YRBS study $(6 \%$; Centers for Disease Control and Prevention, 2006). It is possible that our data mark the continued overall decrease in weapon carrying noted from 1991 to 2003 (Brener et al., 2004). It could also be that our HPOL youth sample was lower risk than the YRBS samples or that they under-reported their weapon carrying behavior. Future research examining temporal trends both in technology exposures and in weapon-carrying may contribute to understanding more about the social ecology of youth violence.

Several other considerations should be taken into account when interpreting the data: Data are analyzed cross-sectionally and are, therefore, correlational. Temporality is not examined and, as such, causation or directionality is unknown. It is possible that youth who play violent games are more likely to carry weapons; and that youth who carry weapons are more likely to play violent games. Violent games may not necessarily be causing weapon carrying. The findings do suggest however, that there is an important link that warrants further investigation - particularly of a longitudinal nature.

Also, these data are based upon self-report of socially undesirable behaviors. It is possible that youth under- or over-reported their exposures or behaviors. To reduce this possibility, efforts to minimize issues related to selfreport were taken (e.g., computer-based versus face-toface data collection). Process measures, as reported in Table 4, suggest that the outcome was not predicted by the survey experience, including self-reported dishonesty in answering the questions. Moreover, rates of selfreported aggression have been noted as similar to observer-reports in previous research (Espelage, Holt, \& Henkel, 2003).

It should be noted also that weapon carrying was measured for the last month, whereas game playing was measured for the past 12 months. It is possible that associations would be different if weapon carrying was also measured for the past 12 months.

\section{CONCLUSION}

As one of the first studies of violent video, computer, and Internet game play and weapon carrying at school, findings should be interpreted cautiously. Not all youth who carry weapons to school play violent video and computer games, and certainly not all youth who play violent video and computer games bring weapons to school. Furthermore, because data are from a community sample of children and young adolescents, low rates of weapon carrying are noted. Our findings need to be replicated before strong conclusions should be drawn. At the same time, consistent with the predictions of modern social-cognitive, observational learning theory including desensitization theory (Anderson \& Bushman, 2001; Huesmann, 1988, 1998; Huesmann \& Kirwil, 2007), this study supports the hypothesis that an increased risk of carrying weapons to school is associated with more violent game play. The results are also consistent with recent investigations that have reported linkages between violent media consumption and increased risk for seriously violent behavior over time (Boxer et al., 2009). Given these consistencies and the seriousness of the behavioral outcomes of weapon carrying, it is perhaps time for adolescent health professionals to discuss with youth the possible effects of their exposure to violence in the games they play even while replications are pending (Strasburger, 2006).

\section{ACKNOWLEDGEMENTS}

Authors are listed in order of contribution; no senior author is listed. We would like to thank the entire Growing up with Media Study team from the Center for Innovative Public Health Research (formerly Internet Solutions for Kids); Harris Interactive, Johns Hopkins Bloomberg School of Public Health; and the Centers for Disease Control and Prevention, who contributed to the planning and implementation of the study. We also thank Grace Yang at the University of Michigan for her contributions to an earlier draft. Finally, we thank the families for their time and willingness to participate in this study.

The contents of this publication are solely the responsibility of the authors and do not necessarily represent the official views of the CDC. The funders were involved in the design and conduct of the study. They were not responsible for the data collection, management, analysis, and interpretation of the data; nor were they involved in the preparation, review, or approval of the manuscript.

\section{REFERENCES}

American Psychiatric Association. (2000). Diagnostic and statistical manual of mental disorders (DSM-IV-TR). Washington, DC: American Psychiatric Association. 
Anderson, C. A. 2004. An update on the effects of playing violent video games. Journal of Adolescence, 27, 113-122. doi: 10.1016/j. adolescence.2003.10.009

Anderson, C. A., Benjamin, A. J., \& Bartholow, B. D. (1998). Does the gun pull the trigger? Automatic priming effects of weapon pictures and weapon names. Psychological Science, 9, 308-314. doi: 10.1111/14679280.00061

Anderson, C. A., \& Bushman, B. J. (2001). Effects of violent video games on aggressive behavior, aggressive cognition, aggressive affect, physiological arousal, and prosocial behavior: A meta-analytic review of the scientific literature. Psychological Science, 12, 353-359. doi: 10.1111/1467-9280.00366

Anderson, C. A., \& Huesmann, L. R. (2003). Human aggression: A social cognitive view. In M. A. Hogg \& J. Cooper (Eds.), Handbook of social psychology, revised edition (pp. 296-323). London, England: Sage Publications.

Anderson, C. A., Shibuya, A., Ihori, N., Swing, E. L., Bushman, B. J., Sakamoto, A., \& Saleem, M. (2010). Violent video game effects on aggression, empathy, and prosocial behavior in Eastern and Western countries: A meta-analytic review. Psychological Bulletin, 136, 151173. doi: $10.1037 / \mathrm{a} 0018251$

Bachman, J. G., Johnston, L. D., \& O’Malley, P. M. (2001). Monitoring the future: Questionnaire responses from the nation's high school seniors, 2000. Ann Arbor, MI: Institute for Social Research. Retrieved from http://monitoringthefuture.org/datavolumes/2000/2000dv.pdf

Bandura, A. 1977. Social learning theory. New York, NY: General Learning Press.

Baranowski, T., Buday, R., Thompson, D. I., \& Baranowski, J. (2008). Playing for real: Video games and stories for health-related behavior change. American Journal of Preventive Medicine, 34, 74-82. doi: 10.1016/j.amepre.2007.09.027

Bargh, J. A., \& Pietromonaco, P. (1982). Automatic information processing and social perception: The influence of trait information presented outside of conscious awareness on impression formation. Journal of Personality and Social Psychology, 43, 437-449. doi: 10.1037//00223514.43.3.437

Berkowitz, L., \& LePage, A. (1967). Weapons as aggression-eliciting stimuli. Journal of Personality and Social Psychology, 7, 202-207. doi: $10.1037 / \mathrm{h} 0025008$

Boxer, P., Huesmann, L. R., Bushman, B., O’Brien, M., \& Moceri, D. (2009). The role of violent media preference in cumulative developmental risk for violence and general aggression. Journal of Youth and Adolescence, 38, 417-428. doi: 10.1007/s10964-0089335-2

Brener, N., Lowry, R., Barrios, L., Simon, T., \& Eaton, D. (2004). Violence-related behaviors among high school students-United States, 1991-2003. MMWR Morbidity and Mortality Weekly Report, 53, 651-655.

Bureau of Labor Statistics, \& Bureau of the Census. (2006). Current Population Survey. Retrieved July 5, 2006, from http://www.census. gov/cps/

Centers for Disease Control and Prevention. (2006). Youth Risk Behavior Surveillance-United States, 2005. MMWR Morbidity and Mortality Weekly Report, 55, 1-108.

Centers for Disease Control and Prevention. (2008). Youth Risk Behavior Surveillance System. Retrieved from http://www.cdc.gov/HealthyYouth/yrbs/

Cotten, N. U., Resnick, J., Browne, D. C., Martin, S. L., McCarraher, D. R., \& Woods, J. (1994). Aggression and fighting behavior among AfricanAmerican adolescents: Individual and family factors. American Journal of Public Health, 84, 618-622. doi: 10.2105/ajph.84.4.618

Dahlberg, L. L., Toal, S. B., Swahn, M., \& Behrens, C. B. (2005). Measuring violence-related attitudes, behaviors, and influences among youths: A compendium of assessment tools. Atlanta, GA: Centers for
Disease Control and Prevention, National Center for Injury Prevention and Control. Retrieved from http://www.cdc.gov/ncipc/pub-res/pdf/ YV/YV_Compendium.pdf

Dodge, K. A., \& Frame, C. L. (1982). Social cognitive biases and deficits in aggressive boys. Child Development, 53, 620-635. doi: 10.1111/ j.1467-8624.1982.tb03434.x

Donovan, J. E. 1996. Problem-behavior theory and the explanation of adolescent marijuana use. Journal of Drug Issues, 26, 379-404.

Donovan, J. E., Jessor, R., \& Costa, F. M. (1988). Syndrome of problem behavior in adolescence: A replication. Journal of Consulting and Clinical Psychology, 56, 762-765. doi: 10.1037//0022-006X.56.5.762

Duke, N. N., Pettingell, S. L., McMorris, B. J., \& Borowsky, I. W. (2010). Adolescent violence perpetration: Associations with multiple types of adverse childhood experiences. Pediatrics, 125, e778-e786. doi: 10.1542/peds.2009-0597

DuRant, R. H., Krowchuk, D. P., Kreiter, S., Sinal, S. H., \& Woods, C. R. (1999). Weapon carrying on school property among middle school students. Archives of Pediatrics \& Adolescent Medicine, 153, 21-26. doi: 10.1001/archpedi.153.1.21

Espelage, D. L., Holt, M. K., \& Henkel, R. R. (2003). Examination of peergroup contextual effects on aggression during early adolescence. Child Development, 74, 205-220. doi: 10.1111/1467-8624.00531

Ferguson, C. J. (2008). The school shooting/violent video game link: Causal relationship or moral panic? Journal of Investigative Psychology and Offender Profiling, 5, 25-37.

Finkelhor, D., Mitchell, K. J., \& Wolak, J. (2000). Online victimization: A report on the nation's youth. Alexandria, VA: National Center for Missing \& Exploited Children. Retrieved from http://www.unh.edu/ ccrc/pdf/jvq/CV38.pdf

Fisk, S. T., \& Taylor, S. E. (1984). Social cognition. Reading, MA: Addison-Wesley.

Forgays, D. G., Forgays, D. K., \& Speilberger, C. D. (1997). Factor structure of the State-Trait anger expression inventory. Journal of Personality Assessment, 69, 497-507. doi: 10.1207/s15327752jpa $6903 \_5$

Gerbner, G., \& Gross, L. (1976). Living with television: The violence profile. Journal of Communication, 26, 172-194. doi: 10.1111/j.14602466.1976.tb01397.x

Gerbner, G., Gross, L., Morgan, M., Signorielli, N., \& Shanahan, J. (2002). Growing up with television: Cultivation Processes. In: J. Bryant \& D. Zillmann (Eds.), Media effects: Advances in theory and research. (2nd ed., pp. 43-67). Mahwah, NJ: Lawrence Erlbaum Associates, Inc.

Gillmore, M. R., Spencer, M. S., Larson, N. C., Tran, Q. D., \& Gilchrist, L. D. (1998). Childbearing adolescents and problem behavior theory. Journal of Social Service Research, 24, 85-108. doi: 10.1300/ J079v24n01_04

Greitemeyer, T., Osswald, S., \& Brauer, M. (2010). Playing prosocial video games increases empathy and decreases schadenfreude. Emotion, 10, 796-802. doi: 10.1037/a0020194

Hamby, S. L., Finkelhor, D., Ormrod, R. K., \& Turner, H. A. (2004). The juvenile victimization questionnaire (JVQ): Administration \& scoring manual. Durham, NH: Crimes Against Children Research Center.

Huesmann, L. R. 1988. An information processing model for the development of aggression. Aggressive Behavior, 14, 13-24. doi: $10.1002 / 1098-2337$

Huesmann, L. R. 1998. The role of social information processing and cognitive schema in the acquisition and maintenance of habitual aggressive behavior. In: R. G. Geen \& E. Donnerstein (Eds.), Human aggression: Theories, research, and implications for social policy. (pp. 73-109). San Diego, CA: Academic Press.

Huesmann, L. R. 2013. Habitual exposure to media violence in childhood predicts serious aggression and crime in late adolescence and adulthood: Evidence from three longitudinal studies. London, UK: International Communication Association. 
Huesmann, L. R., \& Eron, L. D. (1986). Television and the aggressive child: A cross-national comparison. Hillsdale, NJ: Lawrence ErIbaum Associates, Inc.

Huesmann, L. R., \& Guerra, N. G. (1997). Normative beliefs and the development of aggressive behavior. Journal of Personality and Social Psychology, 72, 408-419.

Huesmann, L. R., \& Kirwil, L. (2007). Why observing violence increases the risk of violent behavior in the observer. In: D. J. Flannery, A. T. Vazsonyi, \& I. D. Waldman (Eds.), The Cambridge handbook of violent behavior and aggression. (pp. 545-570). Cambridge, UK: Cambridge University Press.

Huesmann, L. R., \& Miller, L. S. (1994). Long-term effects of repeated exposure to media violence in childhood. In: L. R. Huesmann (Ed.) Aggressive behavior: Current perspectives. (pp. 153-186). New York, NY: Plenum Press.

Huesmann, L. R., Moise-Titus, J., Podolski, C.-L., \& Eron, L. D. (2003). Longitudinal relations between children's exposure to TV violence and their aggressive and violent behavior in young adulthood: 1977-1992. Developmental Psychology, 39, 201-221. doi: 10.1037/00121649.39.2.201

Huesmann, L. R., \& Taylor, L. D. (2006). The role of media violence in violent behavior. Annual Review of Public Health, 27, 393-415. doi: 10.1146/annurev.publhealth.26.021304.144640

Jamieson, S. 2004. Likert scales: how to (ab)use them. Medical Education, 38, 1217-1218. doi: 10.1111/j.1365-2929.2004.02012.x

Jessor, R. 1987. Problem-behavior theory, psychosocial development, and adolescent problem drinking. British Journal of Addiction, 82, 331342. doi: 10.1111/j.1360-0443.1987.tb01490.x

Jessor, R. 1998. New perspectives on adolescent risk behavior. In: R. Jessor (Ed.) New perspectives on adolescent risk behavior. (pp. 1-10). Cambridge, UK: Cambridge University Press.

Josephson, W. L. 1987. Television violence and children's aggression: Testing the priming, social script, and disinhibition predictions. Journal of Personality and Social Psychology, 53, 882-890. doi: 10.1037/00223514.53.5.882

Kaplowitz, M. D., Hadlock, T. D., \& Levine, R. (2004). A comparison of web and mail survey response rates. Public Opinion Quarterly, 68, 94101. doi: $10.1093 / \mathrm{poq} / \mathrm{nfh} 006$

Leeb, R. T., Barker, L. E., \& Strine, T. W. (2007). The effect of childhood physical and sexual abuse on adolescent weapon carrying. Journal of Adolescent Health, 40, 551-558. doi: 10.1016/j. jadohealth.2007.01.006

Moran, G. F., \& Vinovskis, M. A. (1994). Troubled youth: Children at risk in early modern England, colonial America, and 19th-century America. In: R. D. Ketterlinus \& M. E. Lamb (Eds.), Adolescent problem behaviors: Issues and research. (pp. 1-16). Hillsdale, NJ: Lawrence Erlbaum Associates.

Murnan, J., Dake, J. A., \& Price, J. H. (2004). Association of selected risk factors with variation in child and adolescent firearm mortality by state. Journal of School Health, 74, 335-340. doi: 10.1111/j.17461561.2004.tb06624.x

Nansel, T. R., Overpeck, M. D., Haynie, D. L., Ruan, W. J., \& Scheidt, P. C. (2003). Relationships between bullying and violence among US youth. Archives of Pediatrics \& Adolescent Medicine, 157, 348-353. doi: 10.1001/archpedi.157.4.348
Office of Juvenile Justice and Delinquency Prevention. (1998). Seattle Social Development Project-Methods. Retrieved October 1, 2012, from http://www.ojjdp.gov/jjbulletin/9810_2/g2.html

Schonlau, M., Zapert, K., Simon, L. P., Sanstad, K. H., Marcus, S. M., Adams, J., \& Berry, S. H. (2004). A comparison between response from a propensity-weighted Web survey and an identical RDD survey. Social Science Computer Review, 22, 128-138. doi: 10.1177/ 0894439303256551

Sears, R. R., Rau, L., \& Alpert, R. (1965). Identification and child rearing. Stanford, CA: Stanford University Press.

Sheley, J. F., \& Wright, J. D. (1993). Motivations for gun possession and carrying among serious juvenile offenders. Behavioral Sciences \& the Law, 11, 375-388. doi: 10.1002/bsl.2370110405

Spielberger, C. D., \& Reheiser, E. C. (2004). Measuring anxiety, anger, depression, and curiosity as emotional states and personality traits with the STAI, STAXI and STPI. In: M. J. Hilsenroth \& D. L. Segal (Eds.), Comprehensive handbook of psychological assessment. (Vol. 2, pp. 7086). Hoboken, NJ: John Wiley \& Sons, Inc.

StataCorp. (2009). Stata statistical software (release 11) [computer program]. College Station, TX: StataCorp LP.

Strasburger, V. C. 2006. "Clueless": Why do pediatricians underestimate the media's influence on children and adolescents? Pediatrics, 117, 1427-1431. doi: 10.1542/peds.2005-2336

Udry, J. R. (1996). The national longitudinal study of adolescent health (AddHealth) [Wave I and Wave II]. Chapel Hill, NC: UNC Carolina Population Center. Retrieved from http://www.cpc.unc.edu/projects/ addhealth

Vossekuil, B., Fein, R., Reddy, M., Borum, R., \& Modzeleski, W. (2002). The final report and findings of the safe school initiative: Implications for the prevention of school attacks in the United States. Washington, D.C.: U.S. Department of Education, Office of Elementary and Secondary Education, Safe and Drug-Free. Schools Program, U.S. Secret Service and National. Threat Assessment Center. Retrieved from http://www.secretservice.gov/ntac/ssi_final_report.pdf

Webster, D. W., Gainer, P. S., \& Champion, H. R. (1993). Weapon carrying among inner-city junior high school students: Defensive behavior vs aggressive delinquency. American Journal of Public Health, 83, 1604 1608. doi: 10.2105/ajph.83.11.1604

Windle, M., Grunbaum, J. A., Elliott, M., Tortolero, S. R., Berry, S., Gilliland, J. ... Schuster, M. (2004). Healthy passages: A multilevel, multimethod longitudinal study of adolescent health. American Journal of Preventive Medicine, 27, 164-172. doi: 10.1016/j. amepre.2004.04.007

Wolak, J., Mitchell, K. J., \& Finkelhor, D. (2006). Online victimization of youth: 5 years later. (07-06-025). Alexandria, VA: National Center for Missing \& Exploited Children Retrieved from http://www.unh.edu/ ccrc/pdf/CV138.pdf.

Ybarra, M., Diener-West, M., Markow, D., Leaf, P., Hamburger, M., \& Boxer, P. (2008). Linkages between Internet and other media violence with seriously violent behavior by youth. Pediatrics, 122, 929-937. doi: 10.1542/peds.2007-3377

Zillmann, D., Bryant, J., Comisky, P. W., \& Medoff, N. J. (1981). Excitation and hedonic valence in the effect of erotica on motivated intermale aggression. European Journal of Social Psychology, 11, 233252. doi: $10.1002 /$ ejsp. 2420110301 